\title{
Postoperative atrial fibrillation after off-pump coronary artery bypass grafting
}

\author{
Dhruva Sharma ${ }^{1}$ (D)
}

Received: 18 February 2020 /Revised: 14 March 2020 / Accepted: 23 March 2020 / Published online: 8 April 2020

(C) Indian Association of Cardiovascular-Thoracic Surgeons 2020

\section{To The Editor:}

Lohchab and Kumar reported the incidence, pathophysiology, risk factors, and complications of postoperative atrial fibrillation (POAF) after off-pump coronary artery bypass grafting. For perioperative medical management of POAF, the author documented the use of $\beta$-blockers, amiodarone, corticosteroids, and diltiazem [1]. The author did not mention about the use of Ivabradine in reducing POAF. Iliuta and RacAlbu documented that prevention of POAF with combination therapy of metoprolol and ivabradine was more effective than with metoprolol or ivabradine alone during the immediate postoperative management of cardiac surgery patients [2]. Abdel-Salam and Nammas also highlighted that in patients undergoing elective coronary artery bypass grafting, adding ivabradine to $\beta$-blockers during the perioperative period was associated with reduced incidence of atrial fibrillation at 30-day follow-up, compared with either medication alone [3].

Moreover, ivabradine is a selective $I \mathrm{f}$ current inhibitor that reduces the heart rate without affecting cardiac contractility by selective sinus node inhibition, and has been shown to be cardioprotective in the failing heart $[2,3]$. Could the author provide relevant information regarding the use of ivabradine in reduction of POAF.

\section{Compliance with ethical standards}

Conflict of interest The author declares that he has no conflict of interest.

\section{References}

1. Lohchab SS, Kumar A. Post-operative atrial fibrillation after offpump coronary artery bypass grafting. Indian J Thorac Cardiovasc Surg. 2020;36:4-5.

2. Iliuta L, Rac-Albu M. Ivabradine versus beta-blockers in patients with conduction abnormalities or left ventricular dysfunction undergoing cardiac surgery. Cardiol Ther. 2014;3:13-26.

3. Abdel-Salam Z, Nammas W. Atrial fibrillation after coronary artery bypass surgery: can ivabradine reduce its occurrence? J Cardiovasc Electrophysiol. 2016;27:670-6.

Publisher's note Springer Nature remains neutral with regard to jurisdictional claims in published maps and institutional affiliations.

Dhruva Sharma

drsharmadhruva1981@gmail.com

1 Department of Cardiothoracic and Vascular Surgery, SMS Medical College \& Attached group of Hospitals, Jaipur, Rajasthan, India 